\title{
Molten Hydroxide Trapping Process for Radioiodine
}

\author{
January 2003
}

Prepared by

L. D. Trowbridge

L. M. Toth

E. D. Collins 


\title{
DOCUMENT AVAILABILITY
}

Reports produced after January 1, 1996, are generally available free via the U.S. Department of Energy (DOE) Information Bridge:

Web site: http://www.osti.gov/bridge

Reports produced before January 1, 1996, may be purchased by members of the public from the following source:

\author{
National Technical Information Service \\ 5285 Port Royal Road \\ Springfield, VA 22161 \\ Telephone: 703-605-6000 (1-800-553-6847) \\ TDD: $703-487-4639$ \\ Fax: 703-605-6900 \\ E-mail: info@ntis.fedworld.gov \\ Web site: http://www.ntis.gov/support/ordernowabout.htm
}

Reports are available to DOE employees, DOE contractors, Energy Technology Data Exchange (ETDE) representatives, and International Nuclear Information System (INIS) representatives from the following source:

Office of Scientific and Technical Information

P.O. Box 62

Oak Ridge, TN 37831

Telephone: 865-576-8401

Fax: 865-576-5728

E-mail: reports@adonis.osti.gov

Web site: http://www.osti.gov/contact.html

\begin{abstract}
This report was prepared as an account of work sponsored by an agency of the United States Government. Neither the United States government nor any agency thereof, nor any of their employees, makes any warranty, express or implied, or assumes any legal liability or responsibility for the accuracy, completeness, or usefulness of any information, apparatus, product, or process disclosed, or represents that its use would not infringe privately owned rights. Reference herein to any specific commercial product, process, or service by trade name, trademark, manufacturer, or otherwise, does not necessarily constitute or imply its endorsement, recommendation, or favoring by the United States Government or any agency thereof. The views and opinions of authors expressed herein do not necessarily state or reflect those of the United States Government or any agency thereof.
\end{abstract}


Nuclear Science and Technology Division

\title{
MOLTEN HYDROXIDE TRAPPING PROCESS FOR RADIOIODINE
}

\author{
L. D. Trowbridge \\ L. M. Toth ${ }^{*}$ \\ E. D. Collins
}

Date Published: January 2003

\author{
Prepared by \\ OAK RIDGE NATIONAL LABORATORY \\ P.O. Box 2008 \\ Oak Ridge, Tennessee 37831-6254 \\ managed by \\ UT-Battelle, LLC \\ for the \\ U.S. DEPARTMENT OF ENERGY \\ under contract DE-AC05-00OR22725
}

${ }^{*}$ Harbach Engineering, Dayton, Ohio. 



\section{CONTENTS}

Page

LIST OF FIGURES $\ldots \ldots \ldots \ldots \ldots \ldots \ldots \ldots \ldots \ldots \ldots \ldots \ldots \ldots \ldots \ldots \ldots \ldots \ldots \ldots$

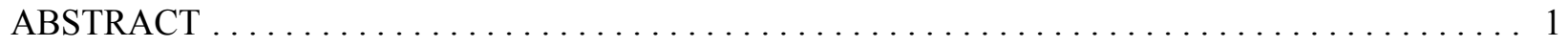

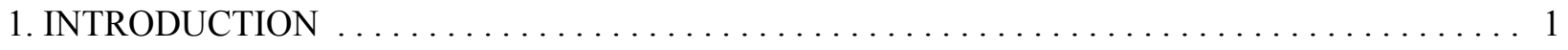

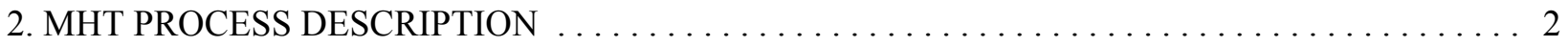

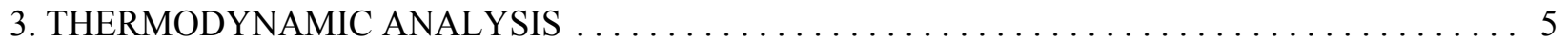

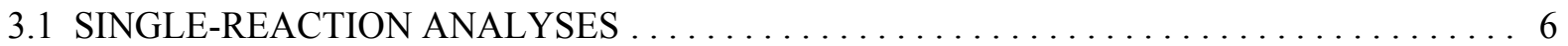

3.2 GLOBAL EQUILIBRIUM CALCULATIONS $\ldots \ldots \ldots \ldots \ldots \ldots \ldots \ldots \ldots \ldots \ldots$

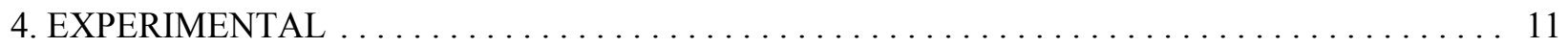

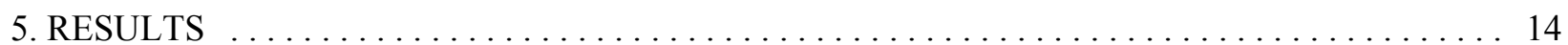

5.1 CRYSTALLIZATION EXPERIMENTS $\ldots \ldots \ldots \ldots \ldots \ldots \ldots \ldots \ldots \ldots \ldots \ldots \ldots$

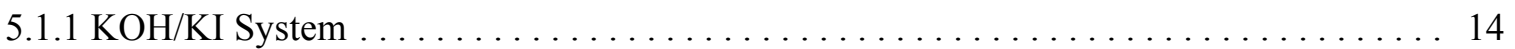

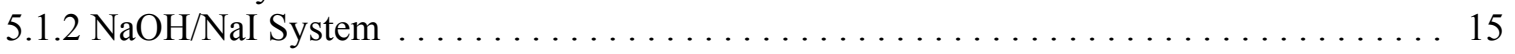

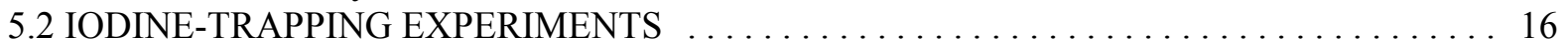

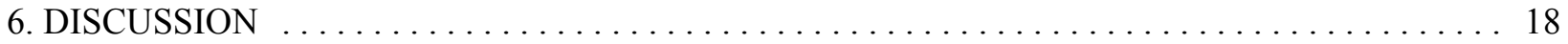

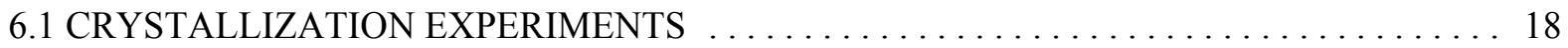

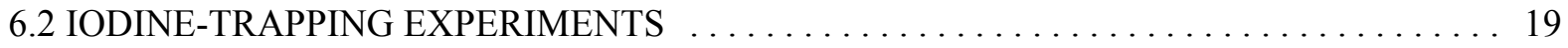

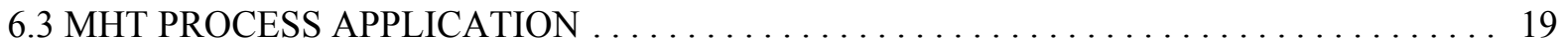

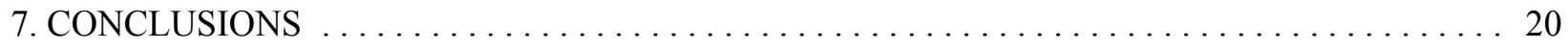

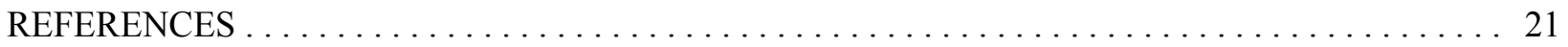

APPENDIX: SOURCES OF THERMODYNAMIC DATA

FOR GLOBAL EQUILIBRIUM CALCULATIONS $\ldots \ldots \ldots \ldots \ldots \ldots \ldots \ldots \ldots \ldots \ldots$ 



\section{LIST OF FIGURES}

$\begin{array}{lll}\text { Figure } & \text { Page }\end{array}$

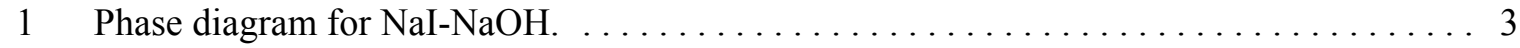

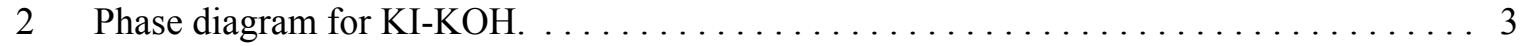

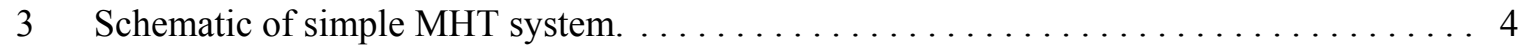

4 Global equilibrium calculation - baseline scenario. ................... 9

5 Global equilibrium calculation - anaerobic scenario. $\ldots \ldots \ldots \ldots \ldots \ldots \ldots \ldots$

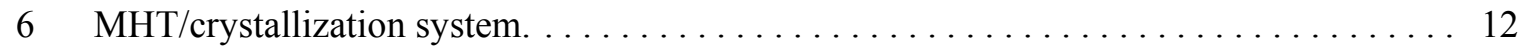

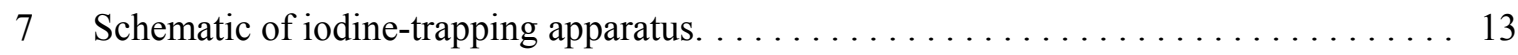

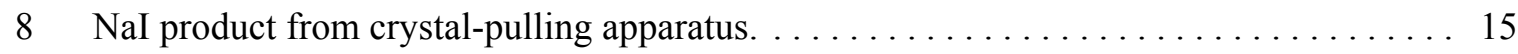





\begin{abstract}
A molten hydroxide trapping process has been considered for removing radioiodine species from off-gas streams whereby iodine is reacted directly with molten hydroxides such as $\mathrm{NaOH}$ or $\mathrm{KOH}$. The resulting product is the corresponding iodide, which can be separated by simple cooling of the molten mixture to grow the iodide primary phase once the mixture reaches $70-80 \mathrm{~mol} \%$ in the iodide component.

Thermodynamic analysis indicates that such a chemical process is highly favorable. Experimental testing of the trapping process using molecular iodine showed trapping of up to $96 \%$ of the volatile iodine. The trapping efficiency was dependent on operational parameters such as temperature and gas-melt contact efficiency, and higher efficiencies are expected as the process is further developed. While an iodide phase could be effectively isolated by slow cooling of a molten iodide-hydroxide mixture, the persistent appearance of hydroxide indicated that an appreciable solubility of hydroxide occurred in the iodide phase.
\end{abstract}

\title{
1. INTRODUCTION
}

Radioiodine release from the nuclear fuel cycle is one of the most serious concerns in utilizing nuclear power. Extensive study ${ }^{1,2}$ has shown that most of this release occurs under normal circumstances during the aqueous fuel-reprocessing operation, with the dissolver off-gas (DOG) containing the major amount of the iodine.

While accidental release of iodine at the power plant is normally prevented by impregnated charcoal filters, ${ }^{2}$ their application to systems that process aqueous DOG streams poses a safety hazard due to the high concentration of $\mathrm{NO}_{x}$ in these streams. The $\mathrm{NO}_{x}$ can interact with the charcoal and produce explosive products. Therefore, a number of other techniques for trapping iodine from off-gas streams have been utilized or proposed over the past decades and have been the subject of considerable study. However, most of these techniques represent a compromise between advantages and limitations, with the result that no entirely ideal method for such iodine removal exists. Furthermore, it has been noted that there have been few novel developments over the past several decades that might help to address some of the more current needs.

With the increasing interest in the transmutation of long-lived actinide and fission products, a simple means of separating, trapping, and converting these products to suitable targets for transmutation in a reprocessing/recycle operation is highly desirable. The focus of interest in this report is radioiodine. However, in the latter part of this report, some consideration is directed toward another fission product that might accompany iodine in the separations operation-namely, ${ }^{14} \mathrm{C}$.

A simple one-stage process is needed to (1) sequester all the potential chemical forms of radioiodine from the off-gas stream and (2) convert them directly to a product that can be used as a neutron target material for subsequent transmutation. Because the reference target material has been identified as sodium iodide, $\mathrm{NaI},{ }^{1}$ a process that produces $\mathrm{NaI}$ from a trapping operation has been sought in this case. The molten hydroxide trapping (MHT) process was conceived for this purpose. The process is described in the following paragraphs, as are the thermodynamic and experimental testing of its potential. This is an interim report that cannot, at the time it is being issued, give a full evaluation. Such an assessment will follow at a later time when and if the current experimental study has been completed. 


\section{MHT PROCESS DESCRIPTION}

It is known ${ }^{1}$ that aqueous caustic $(\mathrm{NaOH}$ or $\mathrm{KOH})$ solutions are effective for scrubbing gas streams of volatile inorganic iodine forms: $\mathrm{HI}, \mathrm{I}_{2}, \mathrm{HOI}$, etc., with the principal component being $\mathrm{I}_{2}$. The products of this aqueous caustic scrubbing operation are iodide ions, $\mathrm{I} 2$ and iodate ions, $\mathrm{IO}_{3} 2$ according to reactions such as

$$
3 \mathrm{I}_{2}(\mathrm{~g})+3 \mathrm{H}_{2} \mathrm{O} \rightarrow 5 \mathrm{I}^{-}+\mathrm{IO}_{3}^{-}+6 \mathrm{H}^{+} \text {. }
$$

The resulting mixed iodine product does not lend itself well to subsequent disposal or target fabrication procedures.

However, if the water were eliminated and the caustic were molten $\left[318^{\circ} \mathrm{C} \mathrm{mp}(\mathrm{NaOH}) ; 360^{\circ} \mathrm{C} \mathrm{mp}\right.$ $(\mathrm{KOH})]$, the resulting reactions would be similar but without the formation of iodate due to the reaction with water. Therefore, the premise is that such a system could offer several advantages, especially in the direct production of a suitable iodide target material for transmutation. It is envisioned that the entire process could be a simple "one-pot" operation, in which the gas stream is sparged through the melt until a large fraction of the molten hydroxide has reacted; and the melt could then be slowly cooled to produce the iodide product. The addition of a small amount of hydrogen gas (e.g., 4\%) would result in a reducing environment for the gaseous iodine species, which are expected to react according to

$$
\begin{gathered}
\mathrm{HI}(\mathrm{g})+\mathrm{NaOH} \rightarrow \mathrm{NaI}+\mathrm{H}_{2} \mathrm{O}(\mathrm{g}), \\
\mathrm{I}_{2}(\mathrm{~g})+\mathrm{H}_{2}(\mathrm{~g})+\mathrm{NaOH} \rightarrow 2 \mathrm{NaI}+\mathrm{H}_{2} \mathrm{O}(\mathrm{g}), \\
\mathrm{CH}_{3} \mathrm{I}(\mathrm{g})+\mathrm{NaOH} \rightarrow \mathrm{NaI}+\mathrm{H}_{2} \mathrm{O}(\mathrm{g})+\mathrm{C}+\mathrm{H}_{2}(\mathrm{~g}),
\end{gathered}
$$

and

$$
\mathrm{HOI}(\mathrm{g})+\mathrm{H}_{2}(\mathrm{~g})+\mathrm{NaOH} \rightarrow \mathrm{NaI}+2 \mathrm{H}_{2} \mathrm{O}(\mathrm{g})
$$

(Similar reactions would occur using molten $\mathrm{KOH}$ in place of $\mathrm{NaOH}$.) At the molten temperature, the water produced would be gaseous and would leave the melt during the sparging operation. Similarly, the hydrogen would stay in the gas phase and the carbon would float to the surface of the molten salt. The iodide product is totally miscible in the molten hydroxide and should, on cooling, behave according to the phase diagrams ${ }^{3}$ shown in Figs. 1 and 2 for the sodium and potassium systems, respectively.

A simple molten-salt gas-sparging system as shown in the schematic (Fig. 3) is all that would be required to trap the radioiodine in a gas stream. The vessel can be a simple stainless steel-flanged pot with a dipleg for introducing the gas below the surface of the melt. The hydroxide can be loaded in the open air; the pot can then be closed and placed in a furnace to heat the system to above the hydroxide melting point (e.g., a temperature of $450^{\circ} \mathrm{C}$ would be adequate). 


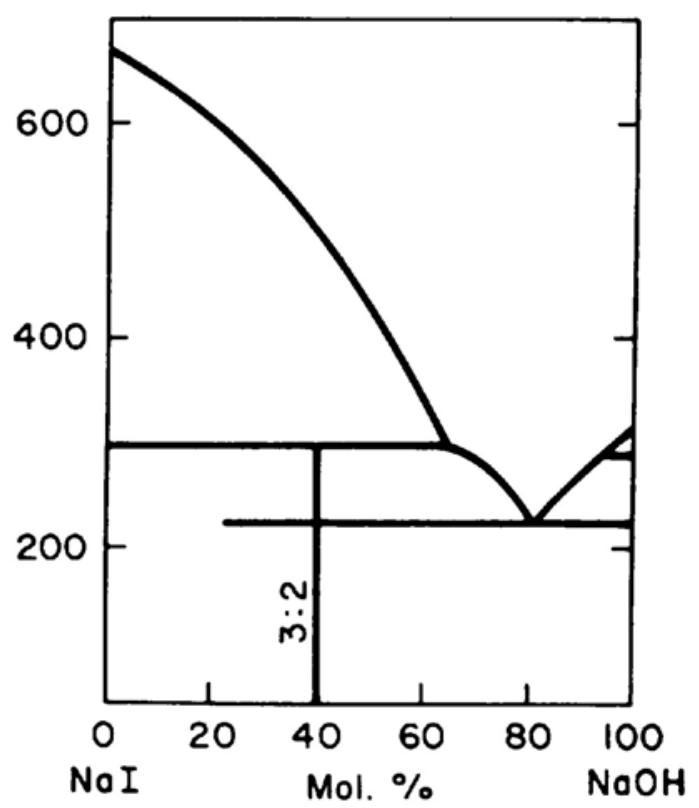

Fig. 1. Phase diagram for NaI-NaOH.

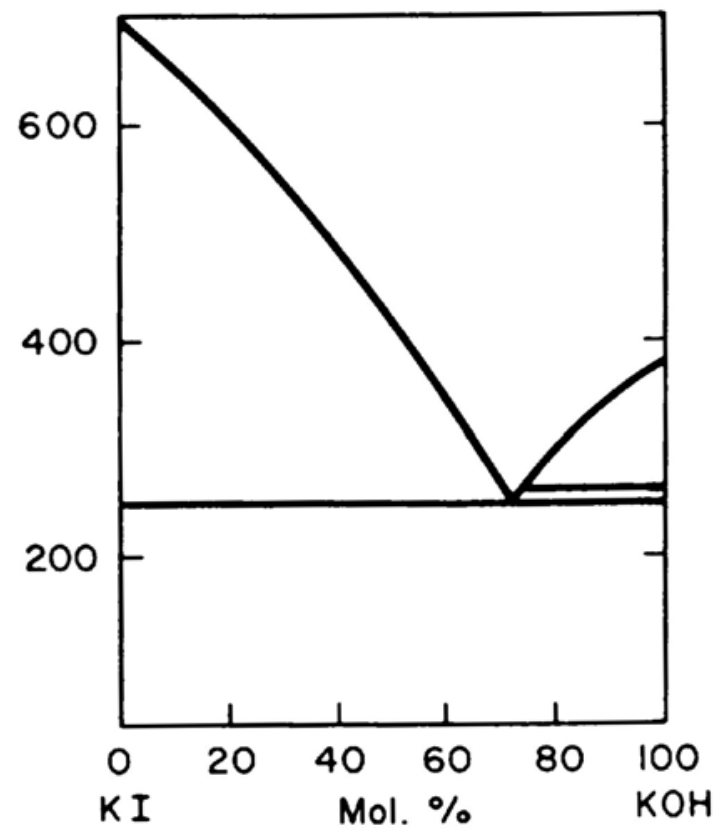

Fig. 2. KI-Phase diagram for KOH. 


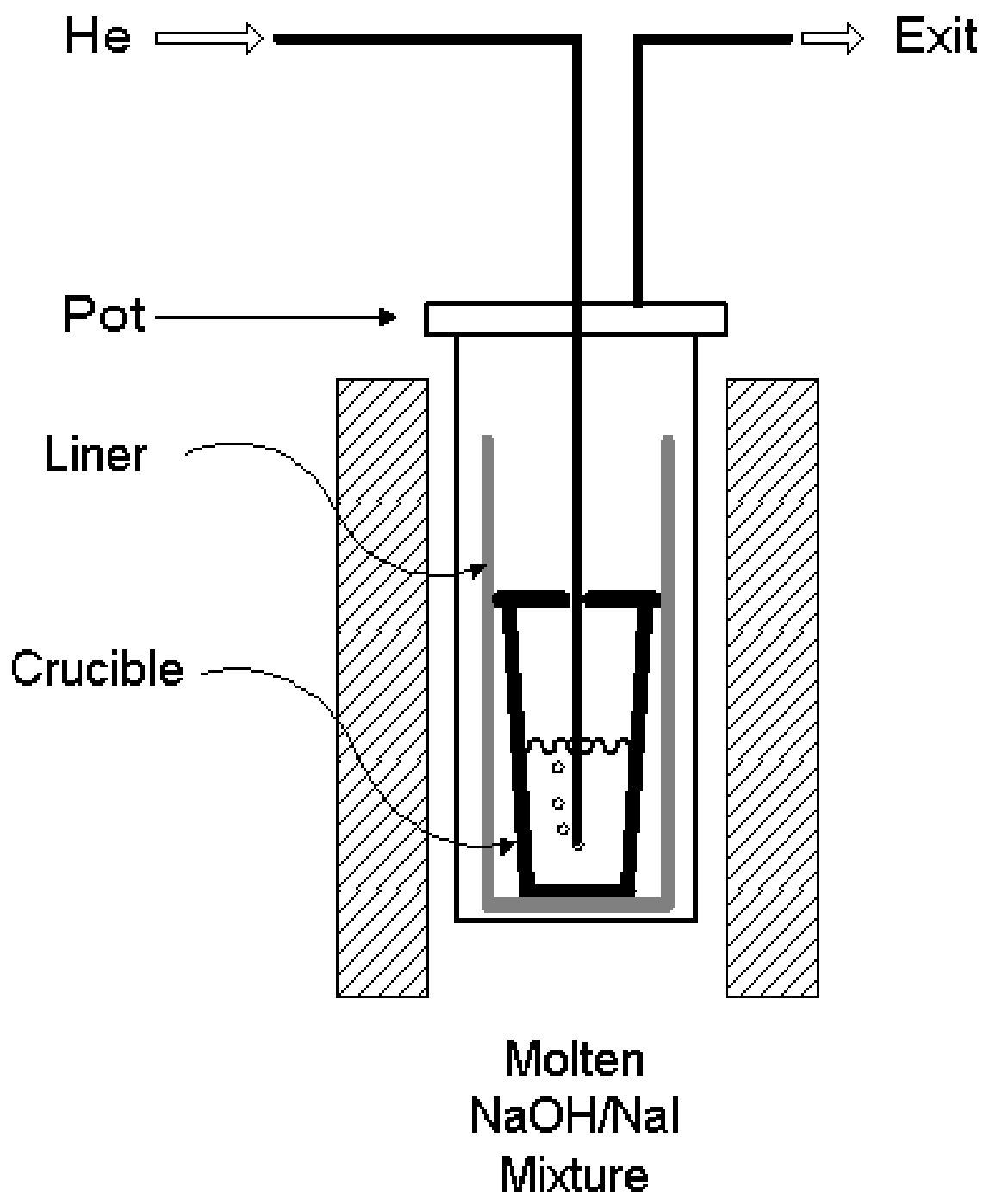

Fig. 3. Schematic of simple MHT system. 
In the ideal case, with no interfering reactions, the iodide product would accumulate in the hydroxide melt as a miscible salt component. The reaction would be allowed to continue until only $20-30 \mathrm{~mol} \%$ of the hydroxide remained. Then upon slow cooling of the melt, the primary iodide phase, which is heavier than that of the mixture, would precipitate until the eutectic temperature was reached, whereupon the remainder of the melt would solidify according to the phase relationships depicted in Figs. 1 and 2. (The growth and precipitation of the primary phase has actually occurred in related systems ${ }^{4}$ as a single-crystal growth process that excludes the remaining solution through the crystallization phenomena.) On reaching ambient temperature, the solidified salt boule could be removed from the pot and the heavier iodide phase (on the lower portion of the boule) manually cleaved from the solid eutectic mass. The iodide portion would then be ready for transmutation irradiation and the eutectic mass returned to the pot with additional hydroxide to replenish that consumed in the above reactions. The pot could be reinserted in the off-gas system for remelting and further iodine trapping. All of these steps could be performed with little difficulty in a hot cell environment.

On comparing the phase diagrams for the sodium and the potassium systems, it is apparent that the potassium system is simpler to use in the above procedure, because cooling a mixture through the iodide primary phase (e.g., 20-30 mol \% $\mathrm{KOH}$ with the balance as $\mathrm{KI}$ ) would produce the iodide phase down to the eutectic point, at which the remainder of the melt would solidify. However, cooling a similar composition in the sodium system would produce the $\mathrm{NaI}$ phase down to approximately $300^{\circ} \mathrm{C}$, where a conversion of the $\mathrm{NaI}$ to $2 \mathrm{NaI} \cdot \mathrm{NaOH}$ would then occur. In order to prevent the formation of the binary compound, the entire system would have to be rapidly quenched from $300^{\circ} \mathrm{C}$ to below the eutectic point or, alternatively, the NaI phase would have to be withdrawn before the mixture cooled below this transition point.

Since this MHT concept has not been considered previously, it was necessary to examine various details of the process. The following sections describe the laboratory testing of the above molten hydroxide process as well as some detailed thermodynamic considerations. The laboratory work is not yet complete, but the following results give some insight into the practicality of such a process. Consideration of the following aspects is necessary for a complete evaluation of this process:

1. the ability to achieve a separation of the iodide phase from the hydroxide phase and the validity of the phase diagrams,

2. the effect of impurities such as $\mathrm{CO}_{2}$ and $\mathrm{NO}_{x}$ components in the gas phase, and

3. modifications to the system to accommodate ${ }^{14} \mathrm{C}$ and ${ }^{3} \mathrm{H}$.

With the exception of tritium trapping, these aspects are discussed, in part, after the thermodynamic considerations in the following paragraphs.

\section{THERMODYNAMIC ANALYSIS}

Two types of thermodynamic analyses were conducted. The first type examined the free energy of specific reactions, the intent being to determine if these reactions are thermodynamically favored. The second type of calculation examined the global equilibrium of complex systems potentially involving many elements and species and taking into account nonideal solution effects in the molten salts. 


\subsection{SINGLE-REACTION ANALYSES}

Analyses of a number of specific single reactions were carried out using the commercial thermodynamics software package HSC. ${ }^{5}$ Thermodynamic data for the chemical species involved in the reactions were taken from the HSC data base without further modification. HSC data for condensed phase species implicitly include phase changes (melting). However, in this mode of operation, solution effects are not incorporated. Free energies were calculated from 200 to $1000^{\circ} \mathrm{C}$.

The reaction of HI with molten $\mathrm{NaOH}$ [Eq.(2)] has a large negative $\Delta \mathrm{G}$ (implying that the products on the right side of the equation are much more stable than the reactants on the left-hand side); its value at $1000^{\circ} \mathrm{C}$ suggests that the partial pressure of $\mathrm{HI}$ would be $4 \mathrm{ppm}$ of the partial pressure of water vapor, implying a high decontamination factor.

The reaction of $\mathrm{I}_{2}(\mathrm{~g})$ with molten $\mathrm{NaOH}$ in a reducing environment [Eq.(3)] has an even larger negative $\Delta \mathrm{G}$ than the reaction in Eq. (2). Note that hydrogen (or another reducing agent) is required on the left side of the equation.

The reaction of methyl iodide with molten $\mathrm{NaOH}$ requires an oxidizer on the left side or a reducing agent on the right side. Since $\mathrm{H}_{2}$ may be present (as excess reagent intended to react $\mathrm{I}_{2}$ ), it was included here in Eq. (4). This reaction has a very large negative $\Delta \mathrm{G}$. From these three reactions, we see that from simple thermodynamic considerations, capture in the molten salt of the three primary chemical forms of volatile iodine is strongly favored, so much so that secondary factors such as solution effects are unlikely to change this conclusion. The need for or production of $\mathrm{H}_{2}$ raises a potential complication if oxygen is present (i.e., air used as a purge).

The reaction of $\mathrm{HOI}$ with molten $\mathrm{NaOH}$ has a fairly large negative $\Delta \mathrm{G}$, favoring reaction of $\mathrm{HIO}$. If normal atmospheric concentrations of water vapor and oxygen are assumed, as written in Eq. (5a), an equilibrium partial pressure of a few parts per million is calculated at $1000^{\circ} \mathrm{C}$ :

$$
\mathrm{HIO}(\mathrm{g})+\mathrm{NaOH}=\mathrm{NaI}+\mathrm{H}_{2} \mathrm{O}(\mathrm{g})+0.5 \mathrm{O}_{2}(\mathrm{~g})
$$

A similarly large negative $\Delta \mathrm{G}$ is found if the reaction is written as originally given in Eq. (5), where a reducing environment is assumed.

The baseline DOG stream composition is specified as consisting of humid air plus those $\mathrm{NO}_{x}$ components that might appear above a nitric acid solution. The primary potentially reactive components of this mixture would be $\mathrm{CO}_{2}, \mathrm{H}_{2} \mathrm{O}$, and nitrogen oxides. For that reason, several impurity reactions were also considered. In the following equation,

$$
\mathrm{CO}_{2}(\mathrm{~g})+\mathrm{NaOH}=\mathrm{Na}_{2} \mathrm{CO}_{3}+\mathrm{H}_{2} \mathrm{O}(\mathrm{g})
$$

the right side of the reaction is favored - that is, over the temperature range calculated $\left(200\right.$ to $\left.1000^{\circ} \mathrm{C}\right)$, thermal decomposition of the carbonate is not predicted. The equilibrium $\mathrm{CO}_{2}$ partial pressure is affected by the water vapor partial pressure so that at $1000^{\circ} \mathrm{C}, 30$-torr water would yield about $60 \mathrm{ppm} \mathrm{CO}_{2}$. This is considerably less than the normal atmospheric $\mathrm{CO}_{2}$ content of $300+$ ppm but implies some $\mathrm{CO}_{2}$ passthrough and raises the possibility of decomposing carbonate using a steam sparge of the molten salt. More detailed calculations would be required to determine if this would be a productive operation, because an increased volume of sparge gas might carry additional iodine from the molten salt. 
For the following hydration reactions,

$$
\mathrm{NaOH}+\mathrm{H}_{2} \mathrm{O}(\mathrm{g})=\mathrm{NaOH} \cdot \mathrm{H}_{2} \mathrm{O}
$$

and

$$
\mathrm{NaI}+2 \mathrm{H}_{2} \mathrm{O}(\mathrm{g})=\mathrm{NaI} \cdot 2 \mathrm{H}_{2} \mathrm{O}
$$

calculated $\Delta \mathrm{G}$ 's are strongly positive. Water vapor should therefore pass through the molten salt without being captured. The $\Delta \mathrm{G}$ for the $\mathrm{NaOH}$ dehydration reaction

$$
2 \mathrm{NaOH}=\mathrm{H}_{2} \mathrm{O}(\mathrm{g})+\mathrm{Na}_{2} \mathrm{O}
$$

is strongly positive (favoring the left-hand side of the equation), implying that even a small influx of water vapor will prevent dehydration of $\mathrm{NaOH}$.

Nitrogen oxide gases can potentially form nitrates and nitrites in the hydroxide melt and might also contribute to oxidation. The reaction

$$
2 \mathrm{NO}_{2}(\mathrm{~g})+2 \mathrm{NaOH}=\mathrm{NaNO}_{3}+\mathrm{NaNO}_{2}+\mathrm{H}_{2} \mathrm{O}(\mathrm{g})
$$

has a fairly large negative $\Delta \mathrm{G}$, implying that most of the $\mathrm{NO}_{2}$ will be trapped; a small partial pressure of $\mathrm{NO}_{2}$ will, however, remain in the gas phase. Nitrates possibly could be "burned" out of the molten salt by sparging with a fuel gas such as hydrogen. The $\Delta \mathrm{G}$ for the reaction

$$
2 \mathrm{NaNO}_{3}(\mathrm{l})+5 \mathrm{H}_{2}(\mathrm{~g})=2 \mathrm{NaOH}(\mathrm{l})+\mathrm{N}_{2}(\mathrm{~g})+4 \mathrm{H}_{2} \mathrm{O}(\mathrm{g})
$$

is quite negative. The presence of oxygen in the sparge gas (i.e., if atmospheric air is used as the carrier gas) would complicate such a scheme, however.

\subsection{GLOBAL EQUILIBRIUM CALCULATIONS}

The previous single-reaction analyses fail to take into account solution effects (including solution nonideality) and interactions among various reactions with common species. Ultimately, such analyses may miss pertinent reactions altogether. A calculation of the global equilibrium of a chemical system involves computation of the minimum free energy state of the system, allowing conversion of the starting materials to whatever mix of products achieves that minimum free energy, within the constraints of elemental mass balance and the possible product species considered.

Global equilibrium calculations were performed using the commercial thermodynamics software ${ }^{6}$ ChemSage (ver. 4.1). Data for the chemical species considered were obtained from the ChemSage inorganic compounds data base or estimated from phase diagrams. A more detailed discussion of the data sources is contained in the Appendix.

A baseline mass balance scenario was developed with reference to an aqueous-reprocessing plant. The major gas stream containing iodine in such a plant is that of the DOG, which can have flow rates of $50-300 \mathrm{~m}^{3} / \mathrm{h}$ for a 5 -ton/day plant. The concentrations of iodine and other components are given in Table 1. 
Table 1. Component concentrations of typical DOG airstream

from a 5-ton/day PWR fuel-processing operation ${ }^{a}$

\begin{tabular}{lc}
\hline Component $^{b}$ & $\mathrm{Ppm} / \mathrm{v}$ \\
\hline Iodine species & $10-100^{c}$ \\
$\mathrm{CO}_{2}$ & 300 \\
$\mathrm{NO}_{x}$ gases & $100-500$ \\
$\mathrm{H}_{2} \mathrm{O}$ & $25,000-30,000$ \\
\hline${ }^{a}$ pressurized-water reactor. & \\
${ }^{b}$ Balance of DOG is other atmospheric components. & \\
& ${ }^{c}$ Principal species is molecular iodine.
\end{tabular}

Preliminary thermodynamic calculations were carried out based on this scenario. For purposes of analysis, the incoming gas stream had a flow of $120 \mathrm{~m}^{3} / \mathrm{h}$; the iodine was partitioned as $90 \% \mathrm{I}_{2}$ and $10 \%$ $\mathrm{HI}$ by mass with a total concentration of $55 \mathrm{ppm}$ by volume; $\mathrm{NO}_{x}$ was assumed to be $\mathrm{HNO}_{3}$ vapor at a concentration of $300 \mathrm{ppm}$; and water vapor was assumed to be $25,000 \mathrm{ppm}$. The scenario examined the equilibrium of 1 day's gas flow reacting with $1600 \mathrm{~g}-\mathrm{mol}(64 \mathrm{~kg}) \mathrm{NaOH}$, a quantity that yields a plausible superficial gas velocity in the salt. Runs were made at temperatures ranging from 600 to $1000 \mathrm{~K}\left(327\right.$ to $\left.727^{\circ} \mathrm{C}\right)$.

The initial calculation treated the balance of the gas as air $\left(78 \% \mathrm{~N}_{2}, 21 \% \mathrm{O}_{2}\right.$, and $\left.1 \% \mathrm{Ar}\right)$. The equilibrium computed in the initial calculation resulted in formation of nitrates from atmospheric $\mathrm{N}_{2}$ and $\mathrm{O}_{2}$, a process that is kinetically inhibited and therefore unlikely to occur at these temperatures. The computation was redone in a way that prevented the reaction of atmospheric $\mathrm{N}_{2}$, yielding more plausible results. Global equilibrium calculations produce a wealth of output which might be examined many ways. However, for brevity the results are summarized in Fig. 4 to show the fraction of iodine and two of the impurity elements (nitrogen and carbon) retained in the gas phase.

Iodine is largely retained in the molten salt phase: $99 \%$ at $727^{\circ} \mathrm{C}(1000 \mathrm{~K})$ and more at lower temperatures. At the higher temperatures, much of the iodine lost to the gas phase is in the form of gaseous NaI, which would condense back to the solid state as soon as the gas stream cooled. After the volatile $\mathrm{NaI}$ was eliminated, the fraction of iodine lost to the gas phase is reduced to $0.02 \%$ at $727^{\circ} \mathrm{C}$. Only a small fraction of the $\mathrm{CO}_{2}$ escapes with the gas phase at any temperature. At the lower temperatures, $\mathrm{NO}_{x}$ is trapped. However, it passes out with the gas phase at temperatures above $550^{\circ} \mathrm{C}$, largely as $\mathrm{N}_{2}$, but also in the form of various $\mathrm{NO}_{x}$ species. Water vapor remained entirely in the gas phase and is not plotted.

In the baseline scenario, the DOG is essentially an oxidizing mixture due to the presence of atmospheric oxygen. There may be some benefit in operating in a reducing mode. An alternate scenario was therefore examined in which the carrier gas was assumed to be $96 \% \mathrm{Ar}$ and $4 \% \mathrm{H}_{2}$. In this scenario, $\mathrm{CO}_{2}$ was reduced to $10 \mathrm{ppm}$ (to represent carbon, including ${ }^{14} \mathrm{C}$, from the processed fuel). All other gas constituents remained as in the baseline scenario. As can be seen in Fig. 5, the addition of $\mathrm{H}_{2}$ and elimination of oxygen significantly reduces the loss of volatile species of iodine and greatly suppresses losses of nitrogen in the form of $\mathrm{NO}_{x}$ species. The fraction of carbon remaining in the gas phase as $\mathrm{CO}$ and $\mathrm{CO}_{2}$ is about the same, still showing a high decontamination factor - $\mathrm{a}$ favorable factor from the point of view of trapping of ${ }^{14} \mathrm{C}$. Sublimed NaI is, of course, essentially the same in both scenarios. 


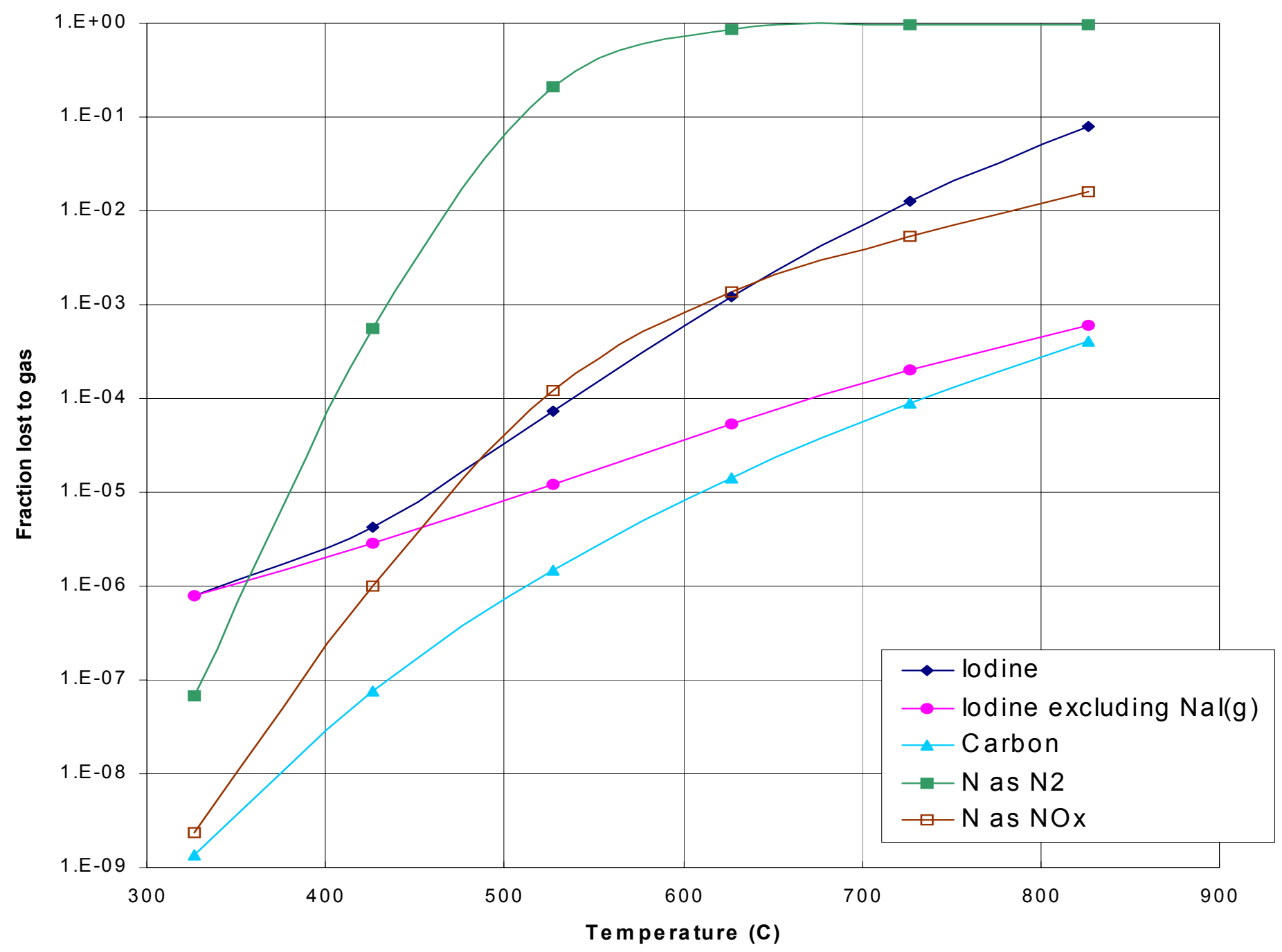

Fig. 4. Global equilibrium calculation-baseline scenario. This synopsis of results shows the fraction of the respective element lost to the exhaust gas stream (e.g., fraction of total carbon lost as $\mathrm{CO}$ or $\mathrm{CO}_{2}$ ). For iodine, most high-temperature losses are due to volatile $\mathrm{NaI}$, which would deposit as soon as the exhaust gas cooled. Two curves are shown, one including this sublimate and the other excluding it. 


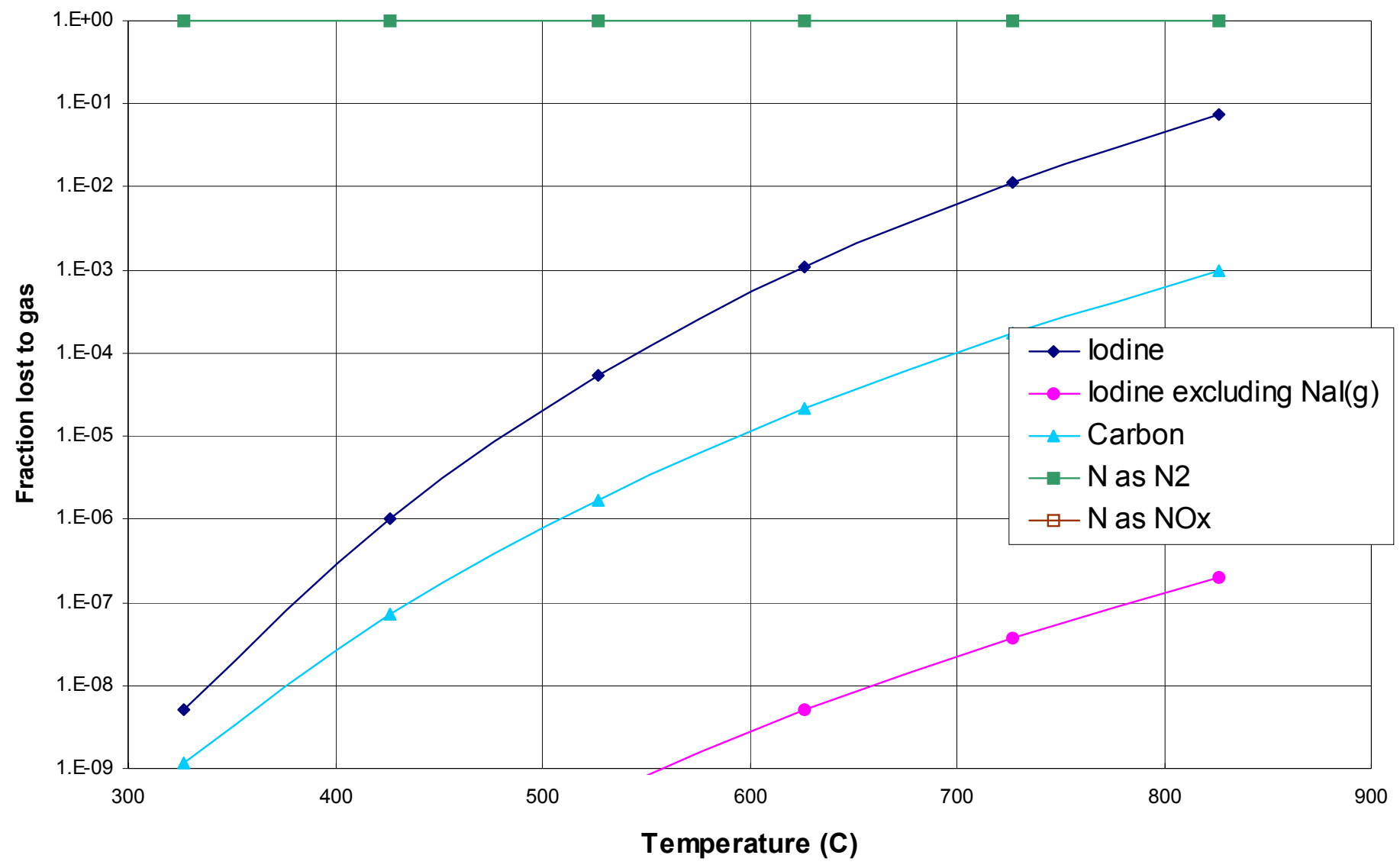

Fig. 5. Global equilibrium calculation-anaerobic scenario. The results assume a reducing environment and show the fraction of the respective element lost to the gaseous exhaust stream. A much smaller fraction of volatile species of iodine $\left(<10^{-7}\right.$, excluding sublimed $\mathrm{NaI}$ ) is retained in the gas phase than was the case in the baseline scenario (an oxidizing environment). The $\mathrm{NO}_{x}$ in the gas phase, off-scale in this diagram, represents $<10^{-12}$ of the nitrogen entering the system. 
These calculations represent the early phase of trapping in a fresh pool of molten $\mathrm{NaOH}$. No solid phase precipitated in these calculations; materials were either trapped in the liquid or remained in the gas phase (though possibly chemically altered). Successive runs could be made representing additional days or weeks of trapping; eventually solid phases would form (notably $\mathrm{NaI}$ and, if present, $\mathrm{Na}_{2} \mathrm{CO}_{3}$ ).

The global equilibrium calculations bear out the main conclusions of the single-reaction calculations. The global equilibrium results are more favorable than the single-reaction calculations in terms of avoiding $\mathrm{NO}_{x}$ buildup in the molten salt but less favorable from the point of view of atmospheric $\mathrm{CO}_{2}$ capture. Both approaches, however, indicate that the thermodynamics of the process are favorable for iodine removal, and high decontamination factors from off-gas are possible.

\section{EXPERIMENTAL}

EM Science Chemical Company was the source of the reagent-grade materials. These materials were used without further purification because it was desirable to examine them as they might occur in an actual process. It is apparent that considerable water and carbonate were present in the hydroxides used, but these impurities are to be expected in typical off-gas streams. On melting, the water will volatilize and be swept away from the pot. The carbonate content will be miscible in the $\mathrm{NaOH}$ melt.

Time did not permit an extensive search for the ideal container material for these molten salts. However, experience with graphite and glassy carbon crucibles encouraged their selection. The great advantage of using these materials was that the molten mixture was nonwetting, thus permitting easy withdrawal of the dipleg prior to cooldown and simple withdrawal of the frozen salt from the crucible. Furthermore, these crucibles are durable enough to be used several times.

The reagents were weighed in the laboratory air and placed in the graphite or glassy carbon crucible, which in turn was placed in a graphite or nickel liner. These components were inserted in a Monel/stainless steel-flanged pot of 3-in. schedule 40 pipe $\times 15$-in. length, which is of standard design for molten salt work in this laboratory. A 1/8-in. nickel tube was inserted through a Teflon slip joint in the flange and attached to the Poco AXF grade graphite dipleg via a special 1/4-in. $\times 20$ threaded connector. See the photo in Fig. 6.

The gas flow exited the containment pot through an open fitting at the flange top. Containment in the pot was mainly for protection from splashing molten hydroxide and to minimize the exposure of the molten hydroxide to carbon dioxide in the laboratory. Products of the reaction were water vapor and unreacted hydrogen (initially $4 \%$ ), which required no trapping prior to venting into the laboratory fume hood. However, when trapping efficiencies were being determined, the exit opening was connected to a line (metal-to-glass transition) leading to an aqueous hydroxide trap, which could be analyzed for iodide breakthrough from the MHT pot. (Details of the gas supply and trapping system are provided in a later paragraph.)

The system was heated in a standard Watlow furnace, placed vertically with the pot inserted to leave the flange outside above the furnace end. This system permitted the pot to be heated to temperatures as high as $1000^{\circ} \mathrm{C}$. An Omega ${ }^{\circledR}$ programmable temperature controller permitted slow programmed cooling of the pot at cooling rates as slow as desired. Typical cooling rates of $10^{\circ} \mathrm{C} / \mathrm{h}$ through the primary-phase region were sufficient for satisfactory crystal growth. 


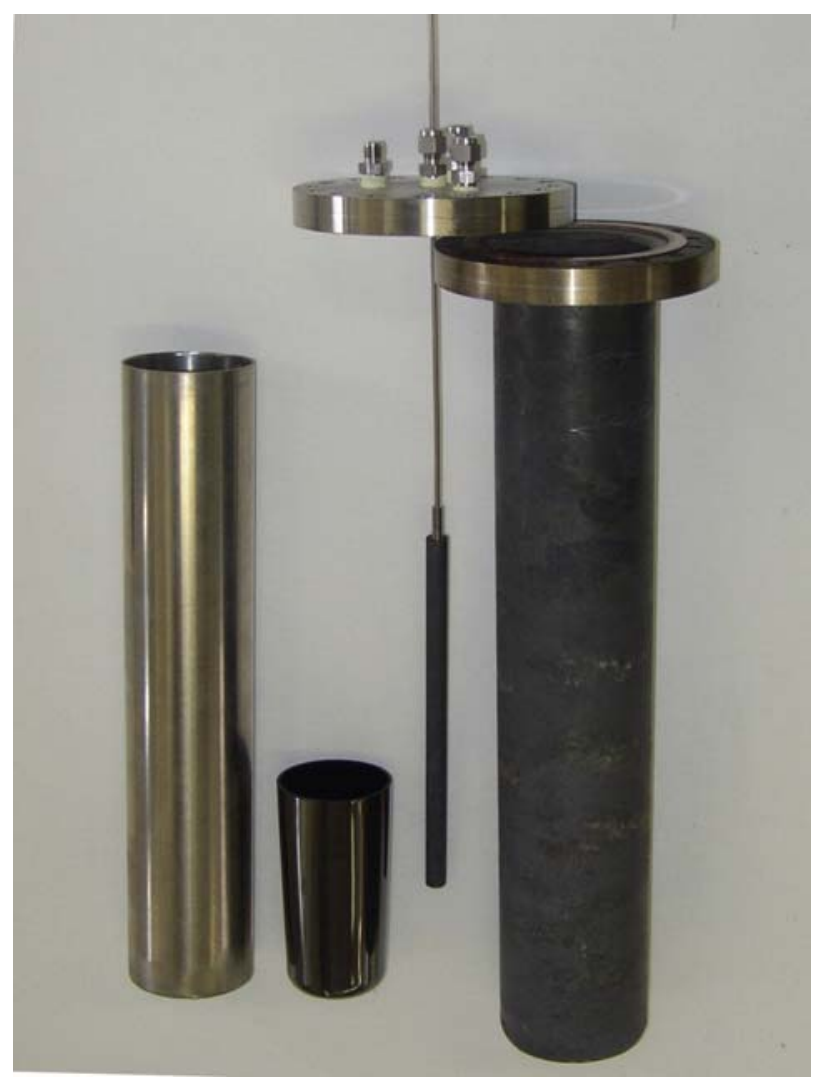

Fig. 6. MHT/crystallization system.

Analysis of the hydroxide content was by simple dissolution and titration with standard acid solution to a phenolphthalein or $\mathrm{pH}$ endpoint. Analysis for iodide was done using an Orion ${ }^{\circledR}$ model 9453BN iodidespecific electrode (ISE) 900200 reference electrode and a 917005 temperature compensation probe, all connected to an Orion model 710 meter. Calibration curves for the ISE were performed using standard solutions in the concentration range and ionic strength of that expected for the samples.

Sample preparation began with weighing the ingredients for the salt mixture $(\mathrm{NaOH}$ only for iodinetrapping experiments, but prescribed proportions of $\mathrm{NaI}$ and $\mathrm{NaOH}$ for crystallization experiments). Due to the hygroscopic nature of the materials, weighing was done expeditiously (accuracy was to $\pm 10 \mathrm{mg}$ on sample weights ranging from 10 to $400 \mathrm{~g}$ ). Moisture pickup during the weighing process did not appear to compromise the weights at this level of accuracy. The weighed ingredients were placed in the carbon crucible, which was in turn loaded into the sheath and outer pot. This was connected to the apparatus and an inert purge was applied to the system prior to heating.

In the crystallization experiments, it was expected that, based on the veracity of the phase diagrams (Figs. 1 and 2), any composition richer than $60 \mathrm{~mol} \%$ in iodide would yield an iodide phase upon cooling the melt. Typically, 70-75 mol \% was selected for the starting composition. The mixture was heated to $600-700^{\circ} \mathrm{C}$ and sparged for $5-10 \mathrm{~min}$ with a 20 - to $30-\mathrm{mL} / \mathrm{min}$ flow of helium through the melt using the graphite dipleg to ensure mixing. The sparge tube was then withdrawn prior to the slow cooldown and solidification of the mixture. After the mixture had reached ambient temperatures, the pot was moved to an inert atmosphere drybox for examination and/or storage of the product. The drybox was necessary to prevent the hygroscopic hydroxide/salt mass from adsorbing moisture and obscuring the phase-boundary 
definition of the product. For analysis, however, selected portions representing primary phase, eutectic remnant, or other phase were taken from the drybox for dissolution, titration, and other tests or observations.

Later crystallization experiments with the sodium system employed a "cold-finger" approach. Such a technique would permit the primary phase to grow on a cold insert that could be withdrawn after the temperature cooldown in the primary-phase region had been traversed but prior to the onset of other phase-transition phenomena. (See Results and Discussion sections.) This cold finger was simply a 1/4-in. stainless steel U-tube with ends protruding through the flange of the pot. One end of the U-tube was connected to an air supply, and the other (the exit end) had a thermocouple inserted down to the curvature to measure the U-tube temperature in contact with the molten mixture. By adjusting the airflow, it was possible to maintain a temperature $50^{\circ} \mathrm{C}$ lower than that of the melt and thus cause the crystal growth to occur on the U-tube. Prior to leaving the iodide temperature region and before ultimate solidification of the remaining mixture had occurred, the U-tube was withdrawn from the melt and left suspended in the upper regions of the containment pot.

In $\mathrm{I}_{2}$-trapping experiments, the supply gas (typically a $96 \% \mathrm{Ar}-4 \% \mathrm{H}_{2}$ mixture) passed through a bed of iodine crystals. A schematic of the apparatus is shown in Fig. 7. The gas then passed through a two-way valve, which could direct the gas either to the molten salt or to an alkaline solution scrubber, which was used to determine the average iodine concentration of the gas. Gas exhaust from the molten salt system passed through a second alkaline solution scrubber to determine the amount of $\mathrm{I}_{2}$ escaping the molten salt. This was the same system used in the crystallization experiments shown in Fig. 3 but with the addition of the $\mathrm{I}_{2}$ source and the alkaline scrubbers.

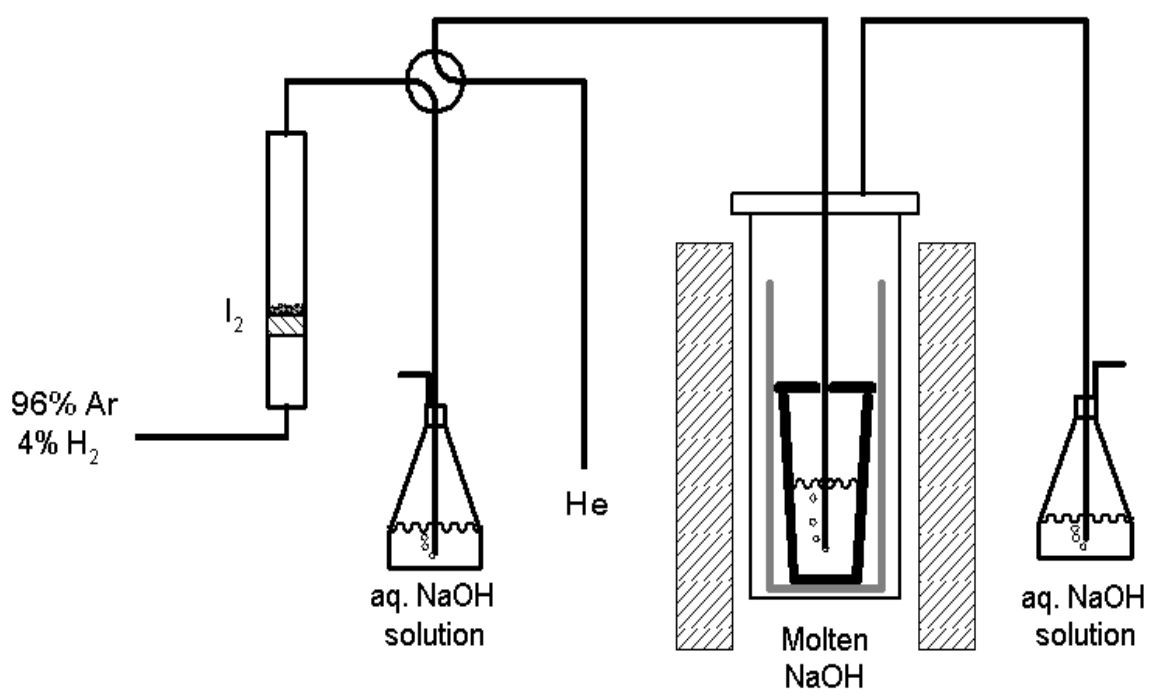

Fig. 7. Schematic of iodine-trapping apparatus. 


\section{RESULTS}

Two major types of tests were performed to evaluate the MHT concept and to learn more about the chemistry of the system. These involved (1) crystallization (designed to determine the phase-separation characteristics of the iodide phase on freezing) and (2) iodine trapping (designed to determine the effectiveness of the MHT process at iodine trapping.

\subsection{CRYSTALLIZATION EXPERIMENTS}

In general, crystallization experiments were designed to demonstrate the ease of producing and separating a pure iodide crystalline phase from a mixture of hydroxide reagent and iodide product by slow cooling of the melt in the composition range where the iodide was the primary phase (see Figs. 1 and 2). Therefore, trusting the validity of the published phase diagrams, the earlier experiments simply followed a procedure of cooling a molten mixture of hydroxide and iodide prepared so that the starting composition would produce an iodide primary phase.

In both the potassium and the sodium systems, at least two distinct separable phases generally appeared. Although analyses typically showed composition differences, there was always substantial hydroxide content in all phases, including the phase identified as "iodide" by reference to Figs. 1 and 2. For that reason, slightly more elaborate methods were used in later crystallization tests. In two of the sodium hydroxide/iodide experiments, a cold finger (cooled $10-50^{\circ} \mathrm{C}$ below the melt temperature) was inserted as cooling of the salt began and then lifted from the melt before the eutectic melting point was reached. Finally, several experiments were performed at higher temperature to determine if iodide could be separated by sublimation from the melt.

\subsubsection{KOH/KI System}

Four $\mathrm{KOH} / \mathrm{KI}$ crystallization experiments were performed with $\mathrm{KOH}$ and $\mathrm{KI}$ mole fractions in the range of 30-35 and 70-65 mol \%, respectively. Referring to Fig. 1, these proportions set the melt composition so that KI was the primary phase that would crystalize from solution on cooling. Only limited analyses were performed in the earliest of the experiments, but these were gradually expanded as the work progressed. The first of the experiments showed promising results in producing two apparently distinct phases. No analyses were, however, performed of the phase compositions. The second experiment produced two visually distinct phases that were subsequently titrated for hydroxide content. The upper phase showed $92 \mathrm{~mol} \% \mathrm{KOH}$, while the lower phase showed $17 \mathrm{~mol} \% \mathrm{KOH}$.

The third experiment included the analysis for iodide ion using the ISE. Leakage of the mixture through the graphite crucible was evident, causing some concern about further use of graphite as a container material. Three distinct regions were apparent within the crucible. Two of these showed similar amounts of increased iodide concentration, while the third that appeared as a sublimate analyzed as pure KI. This observation encouraged the consideration that KI separation might be best achieved by sublimation instead of by selective crystallization.

The fourth experiment showed two distinct phases, with the lower one containing little $\mathrm{KOH}$. However, only $90 \%$ of the mass could be accounted for as KI by titration and ISE measurement. The discrepancies in the mass balance found when the iodide and hydroxide values were calculated led us to consider that considerable carbonate must have also been present in the $\mathrm{KOH}$ starting material. No attempt was made 
to measure this carbonate content other than by acid titration of the $\mathrm{KOH}$ starting material, which showed it to be $92 \%$ by weight $\mathrm{KOH}$.

\subsubsection{NaOH/NaI System}

Several scoping tests were performed prior to an actual attempt to grow a NaI crystal from a melt of NaIrich composition (e.g., $75 \mathrm{~mol} \%$ ). These tests sought to establish the purity of the starting materials and the compatibility of alternate container materials. Of significant interest was the observation that the $\mathrm{NaOH}$ also appeared to have another component, presumably carbonate, because acid titration indicated only $91 \%$ purity. Since these were newly purchased materials and of reagent grade, further efforts to improve the purity were not considered feasible. Furthermore, in the practical application of this MHT process, a significant amount of carbonate impurity in the melt would always be expected.

A simple cooling experiment of this mixture in a manner similar to that in the $\mathrm{KOH} / \mathrm{KI}$ system produced two distinct phases but no significant difference in the NaI content. Realizing that the subsolidus compound $3 \mathrm{NaI}-2 \mathrm{NaOH}$ might form on cooling below $300^{\circ} \mathrm{C}$, it was not surprising that such a result was obtained.

To alleviate this problem of subsolidus-phase transition, a simple crystal-pulling device was fashioned from a U-tube of stainless steel. (See Experimental section.) This device provided a means of growing the $\mathrm{NaI}$ phase on a surface that could be withdrawn from the melt before reaching the $300^{\circ} \mathrm{C}$ phasetransition region. Such a simple device was effective in producing a very high quality crystalline material as shown in Fig. 8. Titrimetric analysis of the NaI phase showed a hydroxide content of $20 \mathrm{~mol} \%$, while the residual salt showed $44 \mathrm{~mol} \% \mathrm{NaOH}$.

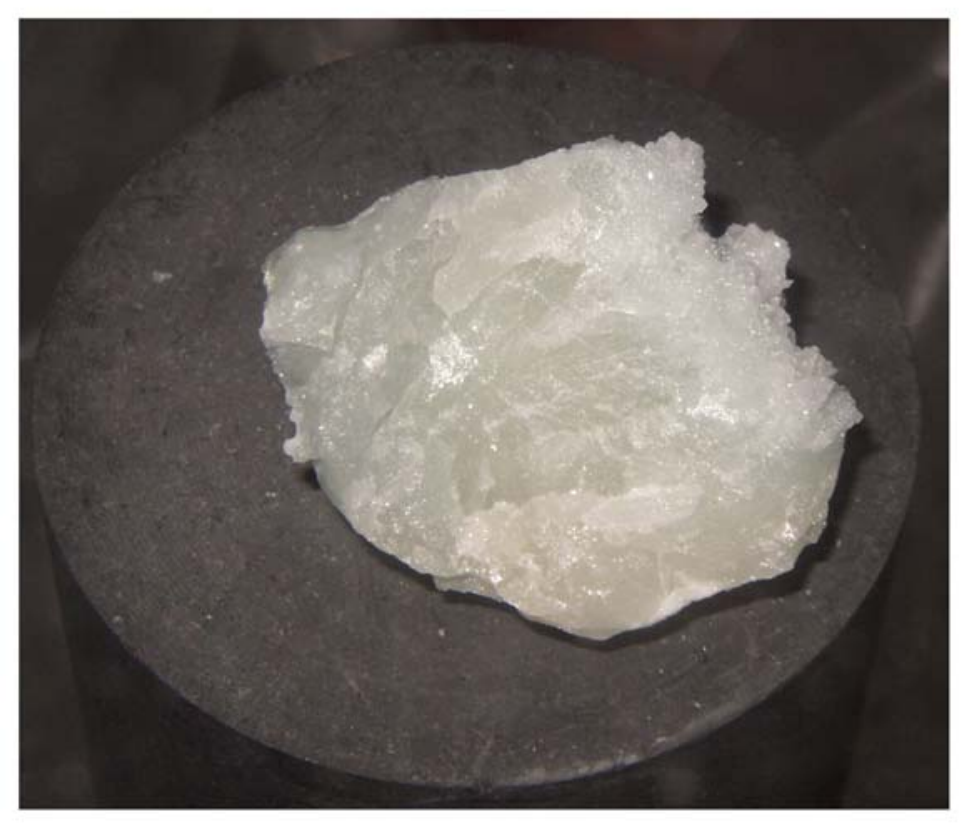

Fig. 8. NaI product from crystal-pulling apparatus. 


\subsection{IODINE-TRAPPING EXPERIMENTS}

Several experiments were conducted to determine if iodine trapping could practically be achieved in this molten salt system. In these experiments, the source gas was produced by passing a controlled flow of carrier gas through a bed of iodine crystals held at a fixed temperature, thus entraining $\mathrm{I}_{2}$ vapor. The actual iodine content of the source gas was measured by running the gas stream through an alternate path containing a secondary alkali solution (the "bypass" solution) for a fixed period of time and analyzing that solution for iodide using the ISE.

During the trapping test, the source gas was bubbled through molten $\mathrm{NaOH}$, as shown in Fig. 7. All trapping tests used glassy carbon crucibles, which, unlike graphite crucibles, showed no signs of attack or penetration. The dip tube carrying the source gas into the melt, however, was made of graphite. The offgas from this system was bubbled through an alkali scrubber solution to capture iodine that passed through the molten salt. In all cases, iodine was determined by ISE analysis. The two scrubber solutions were analyzed directly; the molten salt itself was (after the experiment) completely dissolved in distilled water and a subsample similarly analyzed. It became apparent that iodine was being held up by absorption in the gas lines and other system components. Therefore, in later experiments, wash solutions of such components were also analyzed to obtain as complete a mass balance picture as possible. For purposes of computing molten salt trapping efficiency, the ratio of iodine content of the post-experiment frozen salt to all iodine found in or downstream of the molten salt was computed. Average operational parameters and results for the four iodine-trapping runs are summarized in Table 2.

Table 2. Operating parameters and results in iodine-trapping experiments

\begin{tabular}{|c|c|c|c|c|}
\hline Experiment ID: & $\mathrm{Na}-5$ & $\mathrm{Na}-6$ & $\mathrm{Na}-7$ & $\mathrm{Na}-8$ \\
\hline Salt temperature, ${ }^{\circ} \mathrm{C}$ & 367 & 394 & 605 & 505 \\
\hline Flow, $\mathrm{sccm}^{a}$ & 69 & 41 & 41 & 31 \\
\hline Duration, $\mathrm{h}$ & 49 & 50 & 67 & 69 \\
\hline $\mathrm{X}\left(\mathrm{I}_{2}\right)$ in source gas, $\mathrm{mol} \mathrm{ppm}{ }^{b}$ & 520 & 1100 & 310 & 650 \\
\hline Dipleg immersion in melt, $\mathrm{cm}$ & 1.5 & 9.2 & 7 & 7 \\
\hline Trap efficiency, $\%$ capture $^{c}$ & 22 & 27 & 72 & 96 \\
\hline
\end{tabular}

The first iodine-trapping experiment (designated "Na-5") was carried out with the molten salt at $370^{\circ} \mathrm{C}$. The sparge tube had been inserted only about $1.5 \mathrm{~cm}$ below the surface of the molten salt and remained in the salt as it cooled. At the end of the experiment, the gas was replaced by helium and the flow reduced to $14 \mathrm{sccm}$. The apparent trapping efficiency was low (22\%). About half the iodine that passed the salt was found outside the salt crucible but in the interior of the stainless vessel, rather than in the aqueous scrubber. 
For the second trapping experiment (Na-6), several factors were changed: the sparge tube was immersed deeper into the melt $(9.2 \mathrm{~cm})$; a higher temperature was used $\left(394^{\circ} \mathrm{C}\right)$; and the flow rate of the source gas was reduced by $40 \%$. After the experiment, all downstream components of the flow path were rinsed and the rinse solutions analyzed (not just the vessel and sheath). Iodine was found in all locations. Although the calculated trapping effectiveness was still low at $27 \%$, this value may have been depressed by iodine in the exit tubing remaining from the prior experiment.

All components in or downstream of the molten salt were thoroughly rinsed in distilled water and then reassembled for the next experiment. That experiment (Na-7) began with a "blank" phase, in which all parameters were set as for a run except that the iodine source vessel was absent from the system. A separate scrubber solution was collected prior to reinstallation of the $\mathrm{I}_{2}$ source. In spite of the cleaning, the solution collected a quantity of iodine equivalent to about $1 \%$ of that found in or past the salt in the later phase of the experiment. This suggests the possibility that without thorough cleaning of the plumbing between experiments, a considerable fraction of the material found could derive from wall deposits from the preceding experiment.

The second phase of experiment Na-7 was operated much as Na-6 but at a higher temperature $\left(605^{\circ} \mathrm{C}\right)$. At the end of the experiment, the $\mathrm{Ar} / \mathrm{H}_{2} / \mathrm{I}_{2}$ flow was replaced with an equivalent flow of helium, which continued as the oven cooled. The sparge tube remained in the salt as it cooled and froze. The apparent trapping effectiveness rose to $72 \%$, with nearly all the "passed" iodine being found in the exit hardware rather than in the scrubber solution. At least some of the iodine found past the salt may derive from transport of wall deposits in the inlet plumbing after the salt cooled.

The final trapping experiment drew on the experience of the previous experiments. Again, all the hardware at or downstream of the molten salt was thoroughly rinsed and dried prior to reassembly. The temperature of the run was $505^{\circ} \mathrm{C}$. At the end of the run $(80 \mathrm{~min}$ before cooldown of the salt began $)$, the $\mathrm{Ar} / \mathrm{H}_{2} / \mathrm{I}_{2}$ flow was shut off and replaced with an equivalent flow of helium, the intent being to purge the inlet line of iodine residues through the molten salt. To minimize any transport as the cooling progressed, the helium flow was reduced when oven cooling began and the sparge tube was retracted from the salt at that time. The apparent trapping effectiveness was quite improved, with $96 \%$ being found in the sparge tube or frozen salt. For this run, the sparge tube was rinsed separately and actually yielded $90 \%$ of the iodine found. On standing in air, the graphite sparge tube was observed to slowly exude hygroscopic salt deposits. The analysis was the result of three successive rinses of the sparge tube. (Rinsing ceased when the quantity of iodine in the rinse solution declined to the point of insignificance.)

Some general comments may be made regarding the results of the trapping experiments.

1. The improved trapping efficiency from experiments $\mathrm{Na}-5$ to $\mathrm{Na}-8$ may well be due more to improvement in experimental technique than to changes in physical conditions.

2. The apparent deposition and mobilization of iodine residues on the flow hardware make interpretation of trapping effectiveness difficult.

3. The observation of high iodine concentration in the sparge tube in run Na-8 suggests that iodine was reacting rapidly with trace deposits of hydroxide on the interior of the sparge tube. This process created a locally much higher concentration of $\mathrm{NaI}$ than average, possibly even precipitating an iodine-rich solid $\left(505^{\circ} \mathrm{C}\right.$ being considerably below the melting point of $\mathrm{NaI}$ ). 


\section{DISCUSSION}

\subsection{CRYSTALLIZATION EXPERIMENTS}

The separation and purification of materials by crystallization has long been a valuable means of chemical processing. The use of this technique in molten salt applications is somewhat more novel. The growth of a pure material from an "off-composition" mixture has the advantage over "on-composition" procedures because it can be performed in a system with less stringent controls of temperature and melt composition.

The off-composition growth procedure can be appreciated by referring to the phase diagrams of Figs. 1 and 2. These diagrams show that the growth of the iodide phase from a melt composition of $70-80 \mathrm{~mol} \% \mathrm{NaI}$ begins when the temperature of the composition reaches approximately $600^{\circ} \mathrm{C}$ and continues as the melt becomes richer in the other (i.e., the hydroxide) component. As the crystal growth continues, the melting point of the remaining mixture would follow the solid-liquid line along the iodide primary-phase region. This crystal growth process would therefore proceed over a range of approximately $300^{\circ} \mathrm{C}$. Fine temperature control is not essential because any fluctuations would only cause small oscillations in the precipitation/dissolution of the primary phase.

Such a simple means of separation/purification has been used successfully to produce single crystals of fluoride binary salts from a molten fluoride mixture ${ }^{4}$ and was therefore the basis for applying this novel technique to radioiodine trapping. The results to date indicate that these two systems are not as simple as was the previous fluoride system. The KI phase from the KOH/KI system (Sect. 5.1.1) showed good purity and separation from the frozen mass. The $\mathrm{NaI}$ phase from the $\mathrm{NaOH} / \mathrm{NaI}$ system did not show comparable purity until the crystal-pulling technique was implemented. Even then, the iodide phase still showed the presence of hydroxide.

The results of the crystal-pulling technique indicate that a solid solution of $\mathrm{NaOH}$ in the $\mathrm{NaI}$ phase exists and can be as high as $20 \%$. The titration of the residual salt showing $44 \%$ residual hydroxide is consistent with that portion of the phase diagram at which the controlled slow cooling of the melt was stopped (i.e., $350^{\circ} \mathrm{C}$ ). Therefore, it has been shown that the crystal-pulling technique is effective in producing a NaI phase even though this phase can hold up to $20 \mathrm{~mol} \%$ of residual hydroxide.

One major difference in the current application from the previously successful fluoride melt purification scheme $^{4}$ is that the melt anions here are iodide and hydroxide. (Previously, they were only fluoride.) When one realizes that the large iodide ion (Pauling radius: $2.16 \AA$ ) occupies a lattice site in the cubic NaI crystal that could also be occupied by the smaller hydroxide ion (Pauling radius: $1.40 \AA$ ), it is reasonable to find that the growth of an iodide phase would naturally involve some hydroxide impurity in that phase. There is no way that a crystallization procedure can further remove such an impurity.

This hydroxide impurity should appear in the phase diagrams as a solid solution in the primary phase. Although the phase diagrams for both the $\mathrm{KOH} / \mathrm{KI}$ and the $\mathrm{NaOH} / \mathrm{NaI}$ systems do not show such a solid solution region, the corresponding $\mathrm{KOH} / \mathrm{KCl}$ and $\mathrm{NaOH} / \mathrm{NaCl}$ diagrams do. We can only conclude from the results obtained in the current crystallization experiments that the former phase diagrams are not correct and that a degree of hydroxide solubility is present in the iodide phases.

The impact of this iodide/hydroxide solid solution should not be viewed as limiting for the MHT process. Some hydroxide in the iodide product would not necessarily preclude its use as a target material in a transmutation operation. If, however, the presence of hydroxide were deemed undesirable, the MHT process could be operated to produce higher consumption of the hydroxide component of the trap by using two or more traps in series. Alternatively, the resulting iodide phase (containing some hydroxide 
solid solution) could be separated from the rest of the melt system, remelted, and then converted to a pure iodide phase by sparging with natural iodine in a HI gas stream.

\subsection{IODINE-TRAPPING EXPERIMENTS}

The trapping of molecular iodine, $\mathrm{I}_{2}$, was shown to be effective if the molten hydroxide was at a sufficient temperature and the depth of the melt was also sufficient. Temperatures as low as $370^{\circ} \mathrm{C}$ and shallow immersion depths of the dipleg were not effective in trapping much of the iodine. However, insertion of the dipleg to $9 \mathrm{~cm}$ and operation at higher temperatures $\left(>500^{\circ} \mathrm{C}\right)$ yielded $90 \%$ trapping efficiencies. It is understandable that greater immersion depths and/or better dispersion of the inlet gas stream into the hydroxide melt would have significant influence on the trapping efficiency. Nevertheless, these results show that molecular iodine can be effectively trapped by this process.

The other iodine species have not yet been tested in similar trapping experiments. There is sufficient reason to believe that similar trapping efficiencies can be obtained for all of the iodine species, because these species are most reactive at the operating temperature. Furthermore, the thermodynamic analysis lends support to these assumptions.

\subsection{MHT PROCESS APPLICATION}

The above results give encouragement to further study of the MHT process. The advantage of this process is that simple compact traps could be used on the exit side of an off-gas process stream to trap any iodine species emanating from the system. Impurity components such as water vapor and nitrogen oxides will not affect the process because the former merely passes through the system with the carrier gas and the latter are likely to be converted to nitrogen and water vapor in a reducing atmosphere.

Carbon dioxide in the off-gas stream will probably be trapped in the molten hydroxide as a carbonate salt. While this might add complications to the simple application of MHT for iodine removal, it does offer the potential for trapping the ${ }^{14} \mathrm{C}$ that would also come through the system off-gas as carbon dioxide. If the off-gas system is closed and maintained as an inert gas or nitrogen, then the small amounts of the carbon coming from the system would be from the fuel itself and therefore rich in the ${ }^{14} \mathrm{C}$ isotope. Under such conditions, trapping in the carbonate form would not burden the MHT process severely. Nevertheless, these aspects must still be investigated.

It is envisioned that several traps would be connected in series so that when the first becomes loaded, it can be removed and the iodide phase separated. [The trap loading corresponding to the degree of hydroxide consumption (i.e., the melt composition) can be determined by turning off the heater power to the pot and observing the temperature at which crystallization begins.] Fresh hydroxide can be added to the eutectic remains and the trap put back on-line at the end of the series. Thus, there is a continual procedure of removing the iodide-saturated trap from the head of the trapping line and adding a recharged trap to the end of the line. The products from this stream would be iodide target material suitable for transmutation in a neutron beam. The ${ }^{14} \mathrm{C}$-carbonate would probably have to be separated from the iodide phase prior to irradiation of the target material. However, the phase diagram of the iodidecarbonate systems indicates that similar selective crystallization separations might be achieved.

Throughput of large gas volumes at high velocities may present problems for any liquid trapping process. Solid sorbents with large surface area have definite advantages under such circumstances. However, if the gas volume is reduced or if the solid sorbents are unloaded into the MHT process as a secondary trap, the final iodide product, which is suitable for direct insertion into a transmutation process, makes it a viable backup process to the solid sorbent materials. 


\section{CONCLUSIONS}

The MHT process offers a novel means of (1) sequestering all species of iodine coming from an aqueous off-gas line with a minimal amount of equipment and handling and (2) converting these species to a transmutable $\mathrm{NaI}$ form. Such a system lends itself readily to hot cell operations downstream from an aqueous process off-gas stream. Although several aspects of the MHT process require further experimental testing and development, there is significant merit in considering it further. 


\section{REFERENCES}

1. Radioiodine Removal in Nuclear Facilities: Methods and Techniques for Normal and Emergency Situations, Technical Report Series No. 201, International Atomic Energy Agency, Vienna, 1980.

2. Jubin, R. T., Airborne Waste Management Technology Applicable for Use in Reprocessing Plants for Control of Iodine and Other Off-Gas Constituents, ORNL-TM-10477, Oak Ridge National Laboratory, Oak Ridge, Tennessee, February 1988.

3. Levin, E. M., C. R. Robbins, and H. F. McMurdie (eds.), Phase Diagrams for Ceramicists, American Ceramic Society, Columbus, Ohio, Vol. 1 (1964) and later volumes in the series.

4. Toth, L. M., "Coordination Effects on the Spectrum of Uranium(IV) in Molten Fluorides," J. Phys. Chem. 75, 631 (1971).

5. Roine, A., HSC Chemistry, versions 4.1 and 5.0, Outokumpu Research Oy, Pori, Finland, 2000 and 2002.

6. Eriksson, G., et al., ChemSage, version 4.1, GTT Technologies, Herzogenrath, Germany, 1999. ChemSage was described by Eriksson in Metall. Trans. B 21B, 1013 (1990). 



\section{APPENDIX: SOURCES OF THERMODYNAMIC DATA FOR GLOBAL EQUILIBRIUM CALCULATIONS}

Thermodynamic equilibrium calculations require data on the chemical stability of individual compounds over the temperature range of interest. Any nonideal effects (e.g., nonideal behavior of gases and nonideal solution behavior) will require additional information.

Data for Pure Compounds: For the pure compounds considered in this study, the data included heats of formation $\left(\Delta \mathrm{H}_{\mathrm{f}}{ }^{\circ}\right)$ and entropy $\left(\mathrm{S}^{\circ}\right)$ at standard conditions $\left(25^{\circ} \mathrm{C}\right.$ and $\left.1 \mathrm{bar}\right)$, and to provide the temperature dependence, the heat capacity as a function of temperature, $\mathrm{C}_{\mathrm{P}}(\mathrm{T})$. For nearly all chemical species considered as potential reactants or products in the global equilibrium calculations, these data were available in the standard ChemSage inorganic compound data base. To better define the molten salt state, however, data for the salts (i.e., $\mathrm{NaOH}, \mathrm{NaI}, \mathrm{Na}_{2} \mathrm{CO}_{3}, \mathrm{NaNO}_{3}, \mathrm{NaNO}_{2}$ ) were divided into separate data entries for the solid state and for the liquid state. For each salt, a run was done to verify that its melting point was reproduced by the altered data set.

Three intermediate compounds were shown on molten salt phase diagrams for which no thermodynamic data could be found in either the ChemSage data base or standard references. Thermodynamic properties required for the three species were estimated by the following technique:

1. The $\Delta \mathrm{H}_{\mathrm{f}}^{\mathrm{o}}$ (standard heat of formation) was chosen so that calculations would match the melting point of the compound as shown in the appropriate phase diagram.

2. The value of $S^{o}$ (the standard entropy) was estimated as the weighted sum of $S^{o}$ for the components of a compound. For example, for the compound $\mathrm{NaOH} \cdot \mathrm{NaNO}_{3}, \mathrm{~S}^{\circ}$ is estimated as $\mathrm{S}_{\mathrm{NaOH}}^{\mathrm{o}}+\mathrm{S}_{\mathrm{NaNO}}^{\mathrm{o}}$.

3. The value of $\mathrm{C}_{\mathrm{P}}(\mathrm{T})$, in units of $\mathrm{J} / \mathrm{mol}-\mathrm{K}$, is provided to ChemSage in the form of a polynomial function:

$$
\mathrm{C}_{\mathrm{P}}(\mathrm{T})=\mathrm{A}+\mathrm{BT}+\mathrm{CT}^{2}+\mathrm{D} / \mathrm{T}^{2} .
$$

Each coefficient (A, B, C, and D) was estimated to be the weighted sum of the corresponding coefficient for the constituents, similar to the estimate for the entropy. For all three compounds, two $\mathrm{C}_{\mathrm{p}}(\mathrm{T})$ sets of polynomial coefficients were required, each valid over a limited temperature range. The values of the estimated parameters for these three species are listed in Table A.1. If a phase transition occurs at the boundary between the two coefficient sets, a heat of transition may be associated with the change.

Data for Nonideal Solutions: It is known from phase diagrams ${ }^{3}$ that binary solutions of these salts are nonideal. ChemSage, while providing the facility to incorporate such effects, does not contain the interaction parameters for the various binary pairs. Binary nonideal solution parameters were therefore determined by (1) assuming regular solution behavior and then (2) adjusting the nonideal solution parameter values until key phase-diagram characteristics (e.g., eutectic temperatures and melting points) matched those of published phase diagrams. 
Table A.1. Estimated thermodynamic parameters for three intermediate species for which no data were found in the literature

\begin{tabular}{|c|c|c|c|c|c|c|}
\hline \multirow[b]{2}{*}{$C_{p}$ Coefficients } & \multicolumn{2}{|c|}{$\begin{array}{c}\mathbf{2 N a O H} \cdot \mathbf{3 N a I} \\
\Delta \mathrm{H}_{\mathrm{f}}^{\mathrm{o}}=! 1,730,400 \mathrm{~J} / \mathrm{mol} \\
\mathrm{S}^{\mathrm{o}}=424.39 \mathrm{~J} / \mathrm{mol}-\mathrm{K}\end{array}$} & \multicolumn{2}{|c|}{$\begin{array}{c}\mathbf{N a O H} \cdot \mathbf{N a N O}_{3} \\
\Delta \mathrm{H}_{\mathrm{f}}^{\mathrm{o}}=! 900,096 \mathrm{~J} / \mathrm{mol} \\
\mathrm{S}^{\mathrm{o}}=180.845 \mathrm{~J} / \mathrm{mol}-\mathrm{K}\end{array}$} & \multicolumn{2}{|c|}{$\begin{array}{c}\mathbf{2 N a O H} \cdot \mathbf{N a N O}_{3} \\
\Delta \mathrm{H}_{\mathrm{f}}^{\mathrm{o}}=1,328,157 \mathrm{~J} / \mathrm{mol} \\
\mathrm{S}^{\mathrm{o}}=245.290 \mathrm{~J} / \mathrm{mol}-\mathrm{K}\end{array}$} \\
\hline & $\begin{array}{c}\mathrm{C}_{\mathrm{p}}(\mathrm{T}) \text { Set 1: } \\
\text { valid from } 298.15 \\
\text { to } 527 \mathrm{~K}\end{array}$ & $\begin{array}{c}\mathrm{C}_{\mathrm{p}}(\mathrm{T}) \text { Set } 2: \\
\text { valid from } 527 \\
\text { to } 650 \mathrm{~K}\end{array}$ & $\begin{array}{c}\mathrm{C}_{\mathrm{p}}(\mathrm{T}) \text { Set 1: } \\
\text { valid from } 298.15 \\
\text { to } 572 \mathrm{~K}\end{array}$ & $\begin{array}{c}\mathrm{C}_{\mathrm{p}}(\mathrm{T}) \text { Set 2: } \\
\text { valid from } 572 \text { to } \\
700 \mathrm{~K}\end{array}$ & $\begin{array}{c}\mathrm{C}_{\mathrm{p}}(\mathrm{T}) \text { Set 1: } \\
\text { valid from } 298.15 \\
\text { to } 572 \mathrm{~K}\end{array}$ & $\begin{array}{c}C_{p}(T) \text { Set 2: } \\
\text { valid from } 572 \text { to } \\
700 \mathrm{~K}\end{array}$ \\
\hline $\mathrm{C}_{\mathrm{p}}-\mathrm{A}$ & $1.26490 \mathrm{E}+03$ & $3.22264 \mathrm{E}+02$ & $-2.25167 \mathrm{E}+02$ & $1.13012 \mathrm{E}+02$ & $3.32175 \mathrm{E}+02$ & $3.12046 \mathrm{E}+02$ \\
\hline $\mathrm{C}_{\mathrm{p}}-\mathrm{B}$ & $-3.58039 \mathrm{E}+00$ & $3.22795 \mathrm{E}-02$ & $1.07490 \mathrm{E}+00$ & 0 & $-7.31461 \mathrm{E}-01$ & 0 \\
\hline $\mathrm{C}_{\mathrm{p}}-\mathrm{C}$ & $3.74161 \mathrm{E}-03$ & $-1.88090 \mathrm{E}-07$ & $-5.29050 \mathrm{E}-04$ & 0 & $1.34184 \mathrm{E}-03$ & 0 \\
\hline $\mathrm{C}_{\mathrm{p}}-\mathrm{D}$ & $-2.26319 \mathrm{E}+07$ & $-2.78190 \mathrm{E}+05$ & $9.37330 \mathrm{E}+06$ & 0 & $-1.80361 \mathrm{E}+06$ & 0 \\
\hline$\Delta \mathrm{H}_{\text {trans }}(\mathrm{J} / \mathrm{mol})$ & $1.44180 \mathrm{E}+04$ & & $7.20900 \mathrm{E}+03$ & & $1.44180 \mathrm{E}+04$ & \\
\hline
\end{tabular}


A regular solution is one in which its nonideality can be represented by an excess free energy term of the following form:

$$
\mathrm{G}_{\mathrm{XS}}=\mathrm{R}_{\mathrm{o}} \mathrm{X}_{\mathrm{A}} \mathrm{X}_{\mathrm{B}}
$$

where $X_{A}$ and $X_{B}$ are the mole fractions of the two (liquid) species under consideration and $R_{0}$ is the regular solution interaction parameter. The nonideal interaction parameter $\mathrm{R}_{\mathrm{o}}$ may be a simple function of $\mathrm{T}$, but in this analysis we used only constant values for $R_{o}$. The values for $R_{o}$ were selected so as to reproduce published phase diagrams. ${ }^{3}$ The numerical values found for the several binary molten salt systems are listed in Table A.2. A negative value for the excess free energy parameter implies that the molten state is more stable than an ideal solution of similar composition (this tends to lower the melting point and vapor pressures of mixtures of the involved species); a positive value implies that the liquid is less stable than an ideal solution, with opposite effects on melting points and vapor pressures.

Table A.2. Regular solution interaction parameter $\mathbf{R}_{0}(\mathrm{~J} / \mathrm{mol})$ for binary salt solutions ${ }^{a}$

\begin{tabular}{|c|c|c|c|c|}
\hline & $\mathrm{NaI}$ & $\mathrm{NaNO}_{3}$ & $\mathrm{Na}_{2} \mathrm{CO}_{3}$ & $\mathrm{Na}_{2} \mathrm{O}$ \\
\hline $\mathrm{NaOH}$ & $! 14,500$ & ! 4,039 & ! 300 & $! 15,425$ \\
\hline $\mathrm{NaI}$ & & 5,000 & 5,250 & $\mathrm{n} / \mathrm{pd}^{b}$ \\
\hline $\mathrm{NaNO}_{3}$ & & & 6,425 & $\mathrm{n} / \mathrm{pd}^{b}$ \\
\hline $\mathrm{Na}_{2} \mathrm{CO}_{3}$ & & & & $! 14,500$ \\
\hline
\end{tabular}

Summary: These considerations result in a data set that is capable of approximately duplicating the phasediagram behavior in all the available published binary phase diagrams. No information was found for ternary, quaternary, or higher mixtures of these sodium salt mixtures. However, a common first-order approximation is to simply use the binary interaction parameters, ignoring higher terms. Within the constraints of this approximation, we now have a data set for ChemSage capable of analyzing any gas-scrubbing scenario involving these components. 



\section{INTERNAL DISTRIBUTION}

1. D. E. Benker

2. E. D. Collins

3. A. G. Croff

4. G. D. Del Cul

5. L. K. Felker

6. C. W. Forsberg

7. J. N. Herndon

8. D. J. Hill

9. A. S. Icenhour
10. J. B. Knauer

11. G. E. Michaels

12. B. D. Patton

13. B. B. Spencer

14. L. M. Toth

15-25. L. D. Trowbridge

26. R. M. Wham

27. D. F. Williams

28. ORNL Laboratory Records-RC, OSTI, CRL

\section{EXTERNAL DISTRIBUTION}

29. D.R. Bennett, Los Alamos National Laboratory, P.O. 1663, Los Alamos, NM 87545

30. W. B. Boore, Westinghouse Savannah River Company, P.O. Box 616, Bldg. 703-45A, Rm. 250, Aiken, SC 29802

31. J. C. Bresee, U.S. Department of Energy-NE-20, Office of Advanced Nuclear Research, FORS, 1000 Independence Ave. SW, Washington, DC 20585

32. C. E. Brown, U.S. Department of Energy-NE-20, GTN, 19901 Germantown Rd., Germantown, MD 20874-1290

33. P. J. Finck, Argonne National Laboratory - East, 9700 S. Cass Ave., Bldg. TD360, Rm. L120A, Argonne, IL 60439

34. K. M. Goff, Argonne National Laboratory - West, P.O. Box 2528, Idaho Falls, ID 83403

35. F. J. Goldner, U.S. Department of Energy-NE-20, Office of Advanced Nuclear Research, FORS, 1000 Independence Ave. SW, Washington, DC 20585

36. R. N. Henry, Idaho National Engineering and Environmental Laboratory, 2525 North Fremont Ave, P.O. Box 1625, Idaho Falls, ID 83415

37. J. W. Herczeg, U.S. Department of Energy-NE-20, Office of Technology and International Cooperation, FORS, 1000 Independence Ave. SW, Washington, DC 20585

38. G.D. Jarvinen, Los Alamos National Laboratory, P.O. 1663, Los Alamos, NM 87545

39. J. J. Laidler, Argonne National Laboratory - East, 9700 S. Cass Ave., Bldg. TD360, Rm. L120A, Argonne, IL 60439

40. G. F. Polansky, Sandia National Laboratories, 1515 Eubank Blvd. SE, Albuquerque, NM 87185-0727

41. T. Rudisill, Westinghouse Savannah River Company, P.O. Box 616, Aiken, SC 29802

42. B. Savage, U.S. Department of Energy-NE-20, GTN, 19901 Germantown Rd., Germantown, MD 20874-1290

43. M. Thompson, Westinghouse Savannah River Company, P.O. Box 616, Aiken, SC 29802

44. T. A. Todd, Idaho National Engineering and Environmental Laboratory, 2525 North Fremont Ave, P.O. Box 1625, Idaho Falls, ID 83415

45. G. F. Vandegrift, III, Argonne National Laboratory - East, 9700 S. Cass Ave., Argonne, IL 60439

46. M. A. Williamson, Argonne National Laboratory - East, 9700 S. Cass Ave., Argonne, IL 60439 